\section{Updated Guidelines for Antiretroviral Postexposure Prophylaxis after Sexual, Injection- Drug Use, or Other Nonoccupational Exposure to HIV - United States, 2016}

New evidence-based guidelines, Updated Guidelines for Antiretroviral Postexposure Prophylaxis after Sexual, InjectionDrug Use, or Other Nonoccupational Exposure to HIV - United States, 2016, are now available online (http://www.cdc.gov/ hiv/guidelines/). The guidelines update and expand the 2005 U.S. Department of Health and Human Services recommendations for clinical care providers regarding nonoccupational postexposure prophylaxis (nPEP) for exposure to human immunodeficiency virus (HIV) outside the health care setting for persons in the United States (1). Materials supporting nPEP guidelines implementation will also be posted online when they become available.

The updated guidelines are intended to assist U.S. clinicians in reducing the occurrence of new HIV infections through effective delivery of nPEP to patients shortly after they have a single exposure outside of health care settings to blood, genital secretions, or other potentially infectious body fluids that might contain HIV. This update incorporates new scientific evidence from human and animal studies and includes pediatric dosing information. The update was prompted by new information regarding the clinical delivery of nPEP, the development of newer, better-tolerated antiretroviral drug regimens with reduced side effects, and new estimates of cost-effectiveness of nPEP as an HIV prevention method. Updated occupational PEP guidelines for use following possible HIV exposures in health care settings were published separately in 2013 (2).

In addition to clinicians who provide medical care to patients, the nPEP guidelines might also be of interest to the following: emergency medicine technicians, social workers, administrators of Crime Victim's Compensation programs, and others caring for sexual assault survivors; specialists in HIV prevention planning, service delivery, policy and legislation; persons with HIV and their partners; administrators of pharmacy assistance programs; and managers of medical assistance programs, health insurance plans, and health systems.

\section{References}

1. Smith DK, Grohskopf LA, Black RJ, et al. Antiretroviral postexposure prophylaxis after sexual, injection-drug use, or other nonoccupational exposure to HIV in the United States: recommendations from the U.S. Department of Health and Human Services. MMWR Recomm Rep 2005;54(No. RR-2). http://www.cdc.gov/mmwr/preview/mmwrhtml/ rr5402a1.htm

2. Kuhar DT, Henderson DK, Struble KA, et al. Updated US Public Health Service guidelines for the management of occupational exposures to human immunodeficiency virus and recommendations for postexposure prophylaxis. Infect Control Hosp Epidemiol 2013;34:875-92. http:// dx.doi.org/10.1086/672271 